\title{
Smart Forest Fire Identification and Notification System Using Iot Based Wireless Sensor Networks
}

\author{
Santhiya $\mathrm{M}^{\mathrm{a}, 1}$, Siva Rathnam $\mathrm{M}^{\mathrm{b}}$, Radha Krishnan $\mathrm{T}^{\mathrm{b}}$, and Nishanth $\mathrm{S}^{\mathrm{b}}$ \\ a Assistant Professor, Rajalakshmi Engineering College, Chennai \\ ${ }^{b}$ UG Scholar, Dept of CSE,Rajalakshmi Engineering College, Chennai
}

\begin{abstract}
Wildlife and wildlife authorities face the problem of animal migration from woodland to residential areas in the present environment. Natural calamities triggered by nature, wind and dry undergrowth will destroy acres of land and consume everything in their way that causes significant harm to both natural and human capital. The proposed system to design an IoT-based system that will be able to detect the fire as soon as possible before the fire spreads over the wide area and prevent poaching. Raspberry interfacing with a temperature sensor, a smoke sensor, webcam and a buzzer. GSM gateway is used to conduct this project to provide the user with the final SMS via given number in simulation program. The temperature sensor used to indicate high and low temperatures, the PIR sensor designed to track human activity on the LCD display, the flame sensor used to signify the intensity of flames and the forest fire observed on the LCD display. Once large, image processing is used to determine the accuracy of the fire rate. Wireless Sensor Network (WSN) for data processing to be used as input data in our control system. WSN comprising of temperature sensor system and GPS module to sense forest fire by measuring the level and sending its position to the server utilizing GSM communication contact and GPS functionality. Raspberry Pi cluster, a complicated computation is broken into multiple parts using MPI, and each component runs on separate raspberry pi device. Such sections will be analysed in sequence and then MPI must merge the output and turn it over to the user, essentially they operate as individual units (but in tandem and together) to produce very quick results.
\end{abstract}

Keywords - Iot,Wireless Sensor Networks, Raspberry Pi, Image Processing, Raspberry Pi Cluster, Mpi ，Sensors, Camera, Gsm Gateway, Gps Module

\section{Introduction}

Wildfire is an unregulated fire that does considerable damage to both natural and human properties. Once the fire starts to erupt it travels exponentially throughout the forest and leads to massive devastation. Some of the triggers for wildfire are lighting, extreme hot and arid conditions, severe drought and unconsciousness among humans. There has been a major devastation in the forest over the last decade, in which most of those casualties were triggered by forest fire. Based on data forest fire from India's Forest Survey, it is reported that about 50\% of forest areas are prone to fire[5-6].

The Australian bushfire, started with significant uncontrolled fires in June 2019. As of January 14, 2020, the fires of this season had burned about 18.6 million hectares destroying more than 5,900 houses. An estimate reveals that one billion animals have been killed and may lead to extinction of some species[11-13]. 


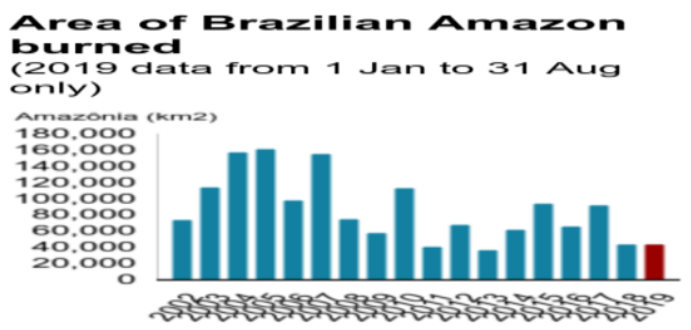

Figure 1. History of Brazilian Amazon Forest fire ratio

The 2019 Amazon rainforest wildfires season fig[1] saw a rise in fires in the Amazon rainforest and Amazon biomes in Brazil, Bolivia, Paraguay and Peru in the Amazon tropical dry season. From a global climate viewpoint, the Amazon has been the main carbon dioxide trap in the world and is expected to absorb up to $25 \%$ of global carbon dioxide emissions into plants and other biomass. Without this drain, atmospheric carbon dioxide emissions will rise, and contribute to higher global temperatures, rendering the survival of the Amazon a global issue. In fact, extra carbon dioxide is released into the atmosphere when the forest is destroyed by fire and could potentially contribute greatly to the overall carbon dioxide content.In this project, we built a forest fire identification and notification system in wireless sensor network for IOT infrastructure to help identify fire as soon as possible, before the fire spreads over the large area. To sense fire and motion the device will be equipped with multiple sensors[10]. After conducting surveys, the device will be placed on proper places. The sensor generated data will be sent to Raspberry pi, which is put in different places. The device will then process the data and concurrently transmit SMS to the nearby fire service station using GPS software using GSM phone with the direction of the explosion. The system uses many forms of sensors: Smoke sensor, PIR sensor, temperature sensor and humidity sensor. The system uses image processing to detect the intensity of the fire when it is at a high rate. Raspberry Pi cluster, a complicated computation is broken into multiple parts using MPI, and each component runs on separate raspberry pi processor. Both pieces will be stored in conjunction and MPI will then merge the product and turn it over to the user, eventually they can function as individual units and deliver results very rapidly

\section{Literature Survey}

On the Forest fire detection system, few works with varied functionalities were proposed and some of the primary papers were referred. Lihong Jiang ,[1] In this proposed design, They had built a data processing system and approved the level for taking the preventive measure. Hamdy Soliman, Komal Sudan [2], The proposed system is used to sense smoke, numerous flammable gasses and fire and alert every hazardous situation using an IoT Dashboard. Hasan Demirel,Turgay celik [3], The author's fire detection system is generalized color model based on rules for classifying flame pixels is used. The performance of the proposed algorithm is tested on two sets of images, one containing fire and the other fire-like regions. Sam G Benjamin [4] ,The Gray-Level Cooccurrence Matrix (GLCM) is used for measuring five fireflames texture attributes. The approach proposed is evaluated on a range of fire and non-fire images, achieving a high detection rate and a low false rate. 


\section{System Architecture}

The proposed system uses an IOT based solution to implement Smart forest fire identification and notification system. The architecture diagram of the smart forest fire identification and notification system is as shown in figure 2 and figure 3 In this proposed system, we have built fire detector using Raspberry Pi which is interfaced with smoke sensor, temperature sensor,PIR sensor, and humidity sensor. The initial phase of forest fire detection is to monitor the temperature level of the forest area, before the fire starts to ignite. If there is any temperature rise or it reaches above the threshold value it pushes the alert message to forest guard and base station via SMS notification. The mapped regions have been sent to the base station for further data processing.

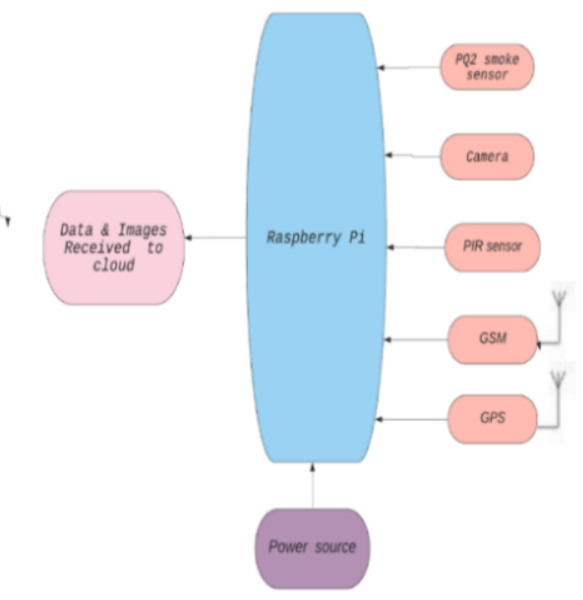

Figure 2. Transmission Unit

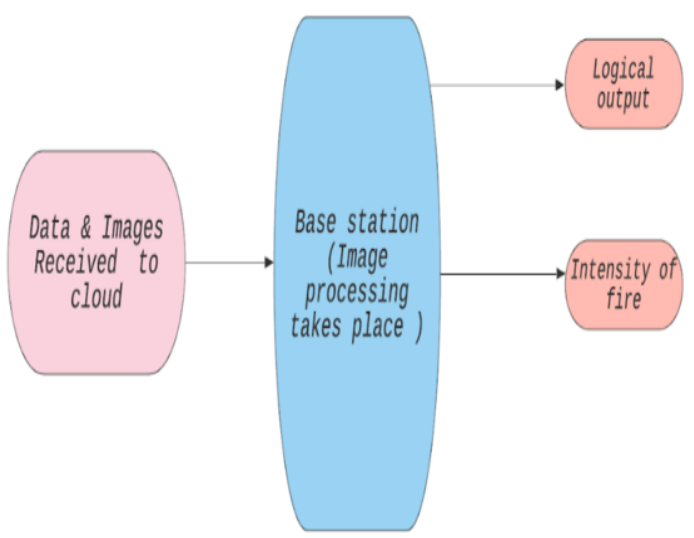

Figure 3. Receiving Unit 
When natural calamities including lightening arise, burning waste material sensors embedded in the Raspberry pi senses[7-9] and sends a signal to the GSM modem's builtin protection mechanism. The Raspberry pi signals are not sent directly to the GSM modem that it converts Analog to Digital and then transmits the signals to the GSM modem from which they are processed. The smoke sensor detects the smoke from the flammable substances and sends an alarm to the base station via GSM gateway. Raspberry pi interfacing sensors, pi camera, GSM and GPS modules function as a relay network by transmitting the real-time data to the base station. Once the fire is identified, the PIR sensor tests whether any person or object is present in the fire-prone zone and then the PIR sensor checks the fire-prone region. The GPS module is used to map the coordinate locations of the forest in terms of latitude and longitude. GPS [15] enabled location is used to map the flame affected forest regions.

Raspberry pi cluster fuses the fragmented tasks into a single unit. Raspberry pi cluster consists of virtualizing nodes in the network. The base station itself serves as the reception device that handles the raspberry pi feedback signals. The base station receiving network consists of virtualized nodes for tracking, minimizing and analysing the data received by the raspberry pi unit. Image processing is the main role that the base station performs in determining the intensity level of the blaze. The Image processing system handles the image data and then analyse them to spot flames. In the images the fire lighting heat signatures and patterns are identified to assess if it is a rapid fire and to act accordingly. At the base station, the GSM notifications and the GPS locations were intimated, and later to the user. Base station consists of slave units to monitor the enormous radius of the forest area. Slave units monitors and transmits regular data to the base station. In case if any node fails, the adjacent node intimates the base station in such a way that fault tolerance is maintained in the proposed system.

\subsection{GPS}

The Global Positioning System is a GPS module to determine the location of a specified region. GPS receivers are used at anytime and anywhere on Earth to provide accurate navigation, positioning and timing services to the consumers. GPS provides data to the receivers via 24 to 32 satellites. GPS module determines location by reading satellite transmitting signals. Each satellite continuously transmits the messages containing the time that has been sent. It is calculated based on the information received from the receiver's position. The raw data received is converted as Latitude and longitude for the user.

\section{2. $G S M$}

The Global System for Mobile communications module is used to connect like a mobile phone over a network. It allows a SIM card to connect over a network and performs the task such as calling, sending, or receiving messages over the network. It can communicate with the PC or microcontroller using the GSM module. The communication between the GSM and the microcontroller is effected by serial communication. 


\subsection{Temperature Sensor}

The temperature sensors may be installed on a substratum of silicon. The temperature sensor notifies the host controller when the ambient temperature exceeds a userprogrammed set-point. The ALERT function can be configured either as a basic comparator of thermostat activities or as an interrupt temperature case. Communication with the sensor is performed via a two-wire bus that conforms to standard industry using protocols.

\subsection{Humidity Sensor}

A sensor (or hygrometer) with moisture senses, controls, and tracks both humidity and air temperature. The level of humidity of air at a specified air temperature to the highest amount of humidity is considered relative humidity. Humidity sensors are used to detect changes that affect electrical currents or air temperature.

\subsection{Raspberry Pi Camera}

The Raspberry Pi in Camera v2 is a Raspberry Pi custom-designed8-megapixel Sony IMX219 image sensor add-on mount, featuring a fixed focus lens. When it comes to still photos, the device is capable of $3280 \times 2464$ pixel static images, and also allows 1080p30, 720p60 and 640x480p90 video.

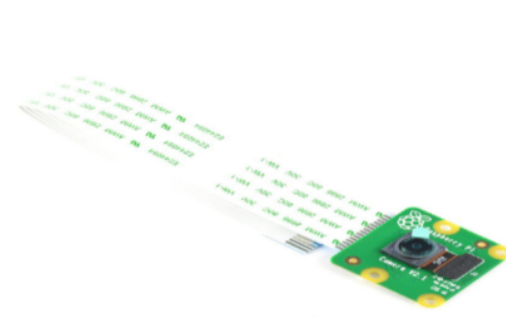

Figure 4. RaspberrypiCamera

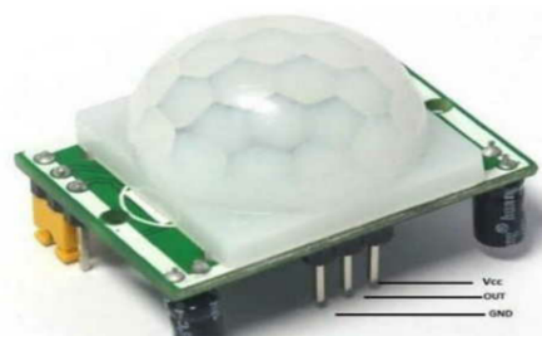

Figure 5. PIR Sensor

\subsection{PIR Sensor}

A passive infrared sensor is an electronic sensor that detects infrared (IR) light in its field of view from objects. We work completely by detecting infrared radiation (radiant heat) emitted from objects or reflected from them.

\subsection{Raspberry PI}

An SD card placed into the board's slot acts as the Raspberry Pi hard drive. It is operated by USB, and the video output can be connected to a conventional RCA TV set, to a more modern display, or even to a Screen seen using the HDMI port in hardware is shown. 


\section{Result}

The system detects the sources of ignition to analyse and predict the risks of flammable items being combusted in the forest. The GPS-based system is used to track and locate the flames in real time and this would prevent a lot of mishaps. The GSM system eliminates system complexity and allows for serial contact between user and base station. The smoke sensor tends to be more reliable and quicker in early detection of a problem that is faster than fire detectors. The Image processing system processes the camera input and then processes it to detect fires. The image data is handled by the Image processing system and then analysed to spot flames. In images, the heat signatures and patterns of fire illumination are detected to determine if it is a rapid fire and to take action accordingly.

Table 1. Test cases with results

\begin{tabular}{|c|c|c|c|c|c|c|}
\hline Test Cases & $\begin{array}{c}\text { Smoke } \\
\text { Sensor }\end{array}$ & $\begin{array}{c}\text { PIR } \\
\text { Sensor }\end{array}$ & $\begin{array}{c}\text { Humidity } \\
\text { Sensor }\end{array}$ & $\begin{array}{c}\text { Pi } \\
\text { Camera }\end{array}$ & $\begin{array}{c}\text { Image } \\
\text { Processing }\end{array}$ & Result \\
\hline Flame detection & $\checkmark$ & $\times$ & $\times$ & $\times$ & $\times$ & $\begin{array}{c}\text { GSM alert is sent to } \\
\text { base station }\end{array}$ \\
\hline $\begin{array}{c}\text { Human inhabitant } \\
\text { and animal detection }\end{array}$ & $\times$ & $\checkmark$ & $\times$ & $\times$ & $\times$ & $\begin{array}{c}\text { GPS information is sent } \\
\text { to base station }\end{array}$ \\
\hline Flame Intensity Level & $\times$ & $\times$ & $\checkmark$ & $\checkmark$ & $\checkmark$ & $\begin{array}{c}\text { Ignition and flame rate } \\
\text { will be determined }\end{array}$ \\
\hline Air pressure & $\times$ & $\times$ & $\checkmark$ & $\times$ & $\times$ & $\begin{array}{c}\text { Calculates the pressure rate } \\
\text { during rapid fire }\end{array}$ \\
\hline Fire Prone Zone & $\times$ & $\times$ & $\times$ & $\checkmark$ & $\checkmark$ & $\begin{array}{c}\text { Monitors and tracks information } \\
\text { via GPS and Image processing }\end{array}$ \\
\hline
\end{tabular}

The above table explains how the forest fire identification and notification system reacts to different test cases. The test cases determines the efficiency of the system to maintain its stability in nature.

\section{Conclusion}

Smart forest fire identification and notification system has been designed to overcome the demerits of existing forest fire detection technologies. The proposed solution transmit useful information that helps in earlier fire detection thus reducing the environmental and ecological cost of impacts. The GSM based system is used for forwarding the message at the time of emergency and the GPS based system transmits the coordinate location in a quick response manner without any delay. The image processing system analyses the intensity of fire level and intimates the accurate results to the user. This system proves to be a noble implementation of sensors in the process of fire identification which makes it cheaper and more efficient.

\section{References}

[1] Stipanicev D., Vuko T., Krstinic D., Stula M., Bodrozic L., Forest Fire Protection by Advanced Video Detection System- Croatian Experiences.Split, Croatia, 2006

[2] Losso A., Corgnati L., Perona G., Early Forest Fire Detection: Smoke Identification through innovative Image Processing using Commercial Sensors. Environment Including Global Change, Palermo, Italy, 2009 
[3] Kovacs R., Kiss B., Nagy A., Vamos R.,Early Forest Fire De-tection System For Vegetable Fire in the Aggtelek National Park. Budpest, Hungary,2004

[4] Kelha V., Rauste Y., Buongiorno A., Forest Fire Detection by Satellites for Fire Control. European Space Agency, Finland, 2000 .

[5] Manyangadze T., Forest Fire Detection for Near Real Time Monitoring using Geostationary Satellite. International Institute for Geo-information Science and Earth Observation, Enschede, Netherland, 2009

[6] Son B., Her Y., Kim J., A Design and Implementation of Forest Fire Surveillance System based on Wireless Sensor Network for South Korea. International Journal of Computer Science and Network Security, Vol 6 No. 9B, September 2006

[7] Hariyawan M.Y., Gunawan A., Putra E.H., Wireless Sensor Network for Forest Fire Detection. ISSN:1693-6930,Vol. 11, No. 3, pp. 563 574, September 2013

[8] P.J Vivek , G. Raju , S. Akarsh, Forest Fire Detection System.International Journal of Innovative Research in Science, Engineering

[9] https://www.express.co.uk/news/world/1224356/Australia-wildfires-map-where-are-Australia-bushfiresnow

[10] Savitha N, S Malathi ,Survey on Fire Safety Measures for Industry Safety using IoT. in the International Conference On Communication And Electronics Systems(ICCES ),, Oct.15-16, 2018

[11] https://www.bbc.com/news/world-49515462

[12] https://tienda.patagoniatec.com/productos/sensor-dht11-con-placa-temperatura-humedad/

[13] https://www.indiamart.com/proddetail/temperature-sensor-3874719197.html

[14] https://www.sparkpcb.com/sensors/mq-2-smoke-combustible-gas-sensor-detector-module.html

[15] V.D.Ambeth Kumar, , Precautionary measures for accidents due to mobile phone using IOT.Clinical eHealth, Volume 1, Issue 1, March 2018, Pages 30-35. 